\title{
Improving nurses' knowledge, attitude, and performance in relation to ethical codes through group reflection strategy
}

\author{
Marzieh Momennasab", Marjan Ghanbari ${ }^{2}$ and Mozhgan Rivaz ${ }^{3 *}$
}

\begin{abstract}
Background: The most basic responsibility of nurses that even precedes their therapeutic role is respect for professional ethics in providing clinical care. The present study was conducted to determine the effect of group reflection on the knowledge, attitude and performance of nurses in relation to ethical codes.
\end{abstract}

Methods: The present blinded, before-after, educational trial was conducted on 86 nurses working at a general hospital in the south of Iran who were randomly divided into a intervention $(n=44)$ and a control $(n=42)$ group. Data were collected before and after the intervention using three tools, including a knowledge test, an attitude rating scale and a performance questionnaire. In the intervention group, the intervention given consisted of four sessions of group reflection, and the control group received a single lecture on ethical codes.

Results: The mean changes in the nurses' score of knowledge after the intervention compared to before differed significantly in both intervention and control groups $(P<0.001)$, but there was no significant difference between the two groups in terms of the mean changes in the score of knowledge $(2.73 \pm 3.45$ in intervention group vs. $2.57 \pm 3.36$ in control group, $P=0.83$ ). Although the mean score of attitude differed significantly between the intervention and control groups in the posttest ( $34.7 \pm 8.44$ in intervention group vs. $29.95 \pm 9.09$ in control group, $P<0.014)$, the two groups were not significantly different in terms of the mean changes in the score of attitude in relation to ethical codes before and after the intervention $(P<0.14)$. Moreover, the two groups were significantly different in terms of the mean changes in the scores of performance in the two stages (9.07 \pm 16.84 in intervention group vs. $0.67 \pm 20.01$ in control group, $P<0.001)$.

Conclusion: Group reflection can improve the knowledge, attitude and performance of nurses in relation to ethical codes. Although lectures can help improve nurses' knowledge and attitude in this area, they have no significant effects on their performance.

Trial registration: Iranian Registry of Clinical Trials (No: IRCT2016070317546N6, registration date: 10 October 2016), https://www.irct.ir/trial/16112

Keywords: Group reflection, Knowledge, Attitude, Performance, Nurses, Codes of ethics

\footnotetext{
* Correspondence: mrivaz@sums.ac.ir

${ }^{3}$ Community Based Psychiatric Care Research Center, Department of Nursing

School of Nursing and Midwifery, Shiraz University of Medical Sciences, Zand

St., Namazee Sq, Shiraz 7193613119, Iran

Full list of author information is available at the end of the article
}

(c) The Author(s). 2021 Open Access This article is licensed under a Creative Commons Attribution 4.0 International License, which permits use, sharing, adaptation, distribution and reproduction in any medium or format, as long as you give appropriate credit to the original author(s) and the source, provide a link to the Creative Commons licence, and indicate if changes were made. The images or other third party material in this article are included in the article's Creative Commons licence, unless indicated otherwise in a credit line to the material. If material is not included in the article's Creative Commons licence and your intended use is not permitted by statutory regulation or exceeds the permitted use, you will need to obtain permission directly from the copyright holder. To view a copy of this licence, visit http://creativecommons.org/licenses/by/4.0/ The Creative Commons Public Domain Dedication waiver (http://creativecommons.org/publicdomain/zero/1.0/) applies to the data made available in this article, unless otherwise stated in a credit line to the data. 


\section{Background}

Ethical codes are ethical values in academic and clinical settings and a prominent aspect of the nursing profession [1]. These codes have been systematically developed in different countries throughout the world, and the Iranian Nursing Codes of Ethics was developed in 2010 with 12 values and 71 professional ethical codes in five domains and was completed and revised in 2012 [2].

Although Iran has developed systematic ethical codes for nurses, adherence to them in clinical settings has reportedly varied in different studies. Some have reported nurses' performance in this area as unfavorable or semifavorable [3, 4] and others as desirable [5-7]. Performance is affected by the individual's knowledge and attitude, especially in the area of ethics, which is influenced by the cultural and social context [8]. One of the reasons for nurses' poor performance in the area of ethical codes is reportedly their lack of knowledge and inadequate training $[4,9,10]$. The notion that being a nurse enables the individual to have an ethical conduct without receiving any training is entirely unfounded [11]. The most important measure that should be taken in order to have capable and ethically-competent nurses who provide quality care is to establish and comply with the principles of professional performance through an emphasis on teaching ethical principles $[12,13]$. Studies have shown that ethical education has a significant positive effect on the promotion of nurses' ethical decisionmaking [14-16].

In Iran "nursing ethics" was added as a specialized course to BSc nursing program from 2014. Before that there was no any independent course in this regard in any levels of nursing education and nursing students had been learned ethical issues through hidden curriculum [17]. Because of this deficit in ethics education, nurses feel the need for training. In a study that investigated nursing ethics priorities on a national level in Iran, the results showed nursing ethics education is the second priority from the nurses' viewpoint [18]. This result revealed the importance of effective ethics education in nursing.

Training nurses should actively develop their independence, critical thinking, open-mindedness and sensitivity to others $[19,20]$. One way for active learning is through reflection. Reflection has been defined as a process of reviewing an experience in order to describe, analyze, and evaluate the performance [21]. This method is a reshaping of experience to improve learning and performance and is effective in increasing nurses' awareness about and skills for clinical care and aims to improve their professional performance [22]. Reflection can also affect the individual's attitude [23] and is particularly important in relation to ethical performance, which is also related to social and cultural conditions [20].
Group reflection is a method of reflection in which, through working in a small group, learners can share their reflections [24] for purposes of education that refers to the participation of groups of people in offering different perspectives on a given problem for better and clearer learning [25]. Thus, in addition to enabling the individual to focus more on and review his experiences, group reflection facilitates the use of different people's views and perspectives [26, 27]. Studies have examined education through reflection and group reflection in different areas and have mostly demonstrated positive effects for these methods [25, 28, 29]. There are some models and frameworks to guide the reflective process. One of them that is used extensively in education and healthcare education.

is that developed by Graham Gibbs (1988) [24]. Gibbs' Reflective Cycle is an extension of Kolb's experiential learning cycle [30] and consist of six steps including description, feeling, evaluation, analysis, conclusion and action plan [31].

Given that most studies conducted on the degree of compliance with ethical codes in nursing have been descriptive, and very few have been interventional (especially in the cultural and social context of Iran), more studies are required to examine the effect of different educational methods on the knowledge, attitude and performance of nurses in this area. The present study was therefore conducted to determine the effect of teaching nursing ethical codes using group reflection on the knowledge, attitude and performance of nurses.

\section{Methods}

The present single-blind, before-after, educational trial was conducted in a hospital affiliated to Shiraz University of Medical Sciences in the south of Iran.

Based on a study conducted by Shadfard in 2014 [32] and taking into account $\alpha=0.05, \beta=0.2$, test power $=0.8$ and potential withdrawal $=10 \%$, the sample size was determined as 45 per group. A total of 90 willing eligible nurses working at different wards of the described hospital were selected. The study inclusion criteria consisted of having a bachelor's degree or higher in nursing, a minimum of 1 month of work experience and not having attended courses on ethical codes from 1 year ago. The study exclusion criteria consisted of more than two sessions of absence from the reflection training, not participating in the pretest or posttest and withdrawal from the project.

To avoid the unwanted exchange of information between the groups during the study, multistage random sampling was performed. At first hospital wards were divided in to control and intervention groups by simple randomization. Participants from hemodialysis, CCU, emergency room, and medical wards were assigned in 
control group and who from ICU, NICU, operating room, pediatrics, and surgical wards were assigned in intervention group. The number of participants from each ward was determined using quotas and then nurses were selected by systematic random approach from the list of nurses working in each ward. The willing candidates entered the study until the group sizes reached 45 . In the course of the study, one subject from the intervention group (for absence from the reflection sessions) and three from the control group (for unwillingness to continue their cooperation) were excluded. Ultimately, the data of 86 nurses (44 in the intervention group and 42 in the control group) were analyzed (Fig. 1).

A demographic questionnaire, a knowledge test, an attitude rating scale and a performance questionnaire were used for data collection.

\section{The knowledge test}

This test was prepared by the researchers based on the available literature on ethical codes and Iranian Nursing Codes of Ethics. It contained seven true/false items and 12 multiple choice items. For each item, the correct answer was given one point and the other answers were scored zero, making the minimum score zero and the maximum 19. To evaluate the content validity of the test, a qualitative content validity assessment was carried out and the questionnaire was distributed among 12 nursing ethics experts and their comments on the content and quality of the designed items were taken. To examine the questionnaire's reliability, the test-retest method was used. The questionnaire was completed by 21 nurses at the interval of 2 weeks. The Pearson correlation coefficient between the two tests was 0.9 .

\section{The attitude rating scale}

This scale was developed by the researchers based on the relevant literature and contained 17 items scored based on a four-point Likert scale. The items assessed nurses' attitude on the necessity, significance and practicality of observing codes of ethics in providing patient care. Each item was scored from zero to three (from 'totally agree' $=3$ to 'totally disagree' $=0$ ), and the minimum score was zero and the maximum 51. To determine the content validity of the scale, the

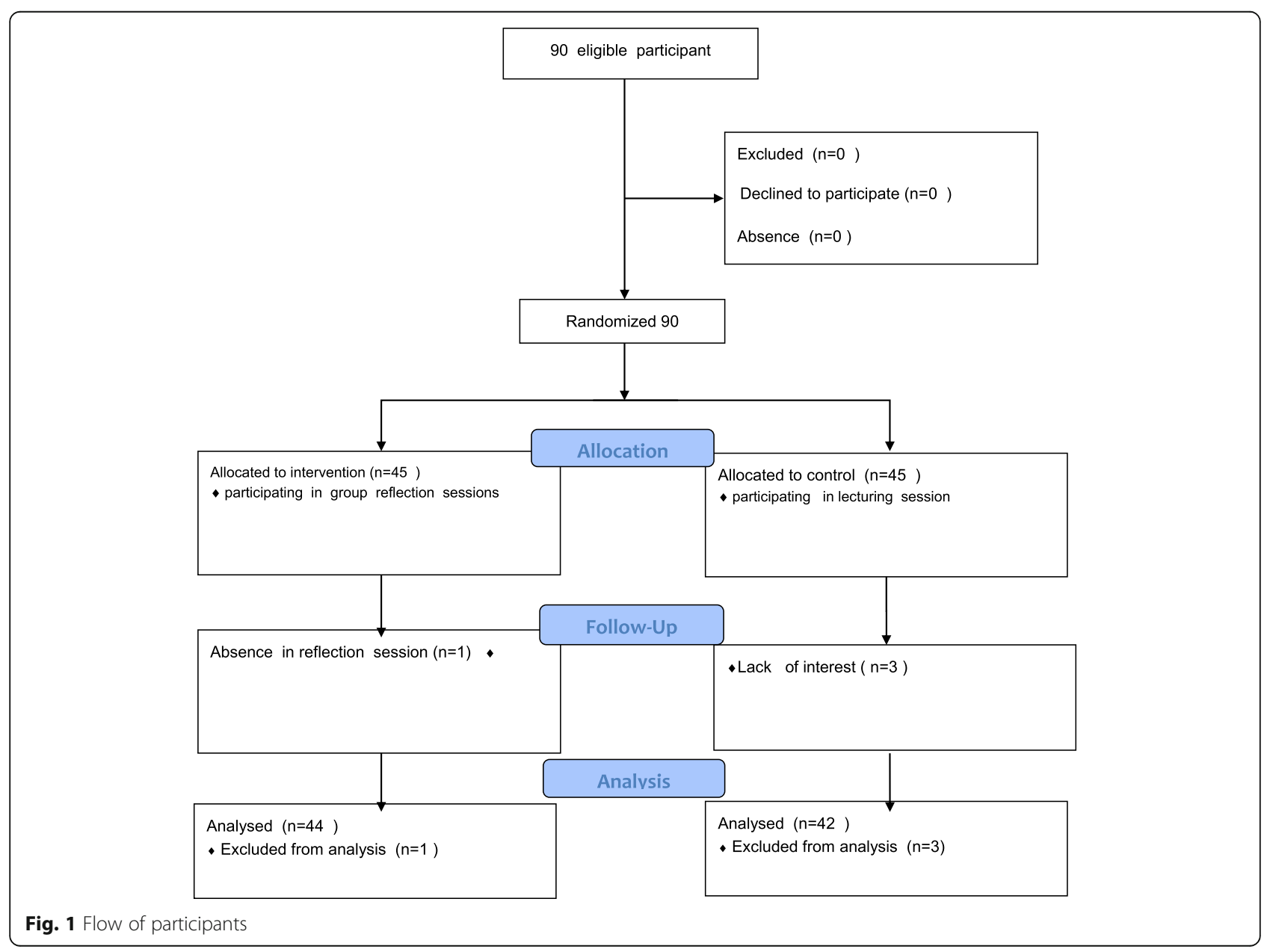


Waltz and Bausell (1983) Content Validity Index (CVI) according to the views expressed by 12 nursing professors was used [33]. For the reliability assessment, the test-retest method was performed and the scale was completed twice by 21 nurses at an interval of 2 weeks, and the Pearson correlation coefficient between the two tests was calculated as 0.94. Also, the Cronbach alpha coefficient of 0.76 showed the favorable internal consistency of the tool [33].

\section{The performance questionnaire}

In the present study, 'performance' indicates nurses' extent of observing ethical codes in providing clinical services. To this end, a questionnaire extracted from the Iranian Nursing Codes of Ethics (the section on Nurses and Practice with 23 codes) was used. This 26-item questionnaire was developed by Moemennsab et al. [6], and has a confirmed validity and reliability. Each item is scored from 0 for 'never' to 3 for 'always', and the minimum and maximum scores are zero and 78 [6]. In the present study, the content validity of the tool was assessed with the views expressed by 12 nursing ethics experts. For the reliability assessment, the questionnaire was completed twice by 21 nurses at an interval of 2 weeks, and the Pearson correlation coefficient between the two tests was calculated as 0.98 . Nurses who participated in the process of assessing the reliability of the questionnaires were not included in the study samples.

The nurses in both the intervention and control groups were first briefed on the study objectives and methods in a session and their informed consents were obtained. They then completed the knowledge, attitude and performance questionnaires. The performance questionnaire was also completed for each nurse by the ward's head-nurse, and the mean of the scores given by the nurses and the head-nurse was taken as the performance score of each subject. The intervention group was divided into five groups of nine, and 4 two-hour group reflection sessions were held for each group in the ward conference room. Each intervention group received two reflection sessions weekly. In each session, two scenarios about observing ethical codes were discussed and reflected on. The scenarios were based on the researchers' experiences and the Nursing Codes of Ethics and used the available resources and were approved by 12 professors at the school of nursing. These scenarios included clinically-tangible issues with which the personnel were faced on a daily basis and included topics such as the importance of obtaining informed consent, respect for the privacy of the patients and their confidentiality, preserving their right to autonomy and decision-making, respect for the patients' personal beliefs, preserving their right to choose to continue the treatment and choose a nurse, the respectful treatment of the patients and other colleagues, and refraining from the commercial promotion of any particular products. Seven questions were posed at the end of each scenario that debated and assessed the subjects' understandings, feelings, views and perspectives and potential decisions.

The reflection sessions were guided by the group leader (researcher) according to the Gibbs model. Gibbs' reflective circle involves description, feeling, evaluation, analysis, conclusion and action plan [31]. In line with this model, questions were asked about each scenario and put to debate. All the principles of group dynamics were fully observed. The control group also received a two-hour lecture by the researcher on issues related to nursing codes of ethics along with a Q\&A and a slide show. The posttest was held in the intervention and control groups 1 month after the last session of group reflection. Moreover, the nurses' performance was assessed by their ward head-nurse, and the mean score of their performance was determined. To blind the study, the distribution and collection of the questionnaires and the statistical analysis of their data were performed by people blinded to the grouping. By the end of the educational intervention and after the posttest, all the participants in both groups were given the discussed scenarios and an educational booklet and a book on nursing ethics.

\section{Ethical considerations}

This study was approved by the research ethics committee of Shiraz University of Medical Sciences (No: IR.SUMS.REC.1395.55). It was also registered in the Iranian Registry of Clinical Trials (No: IRCT2016070317546N6). After receiving explanations about the study, all participants signed a written consent form. They were assured that rejecting participation in the study would have no effect on their professional status and their data would be keptconfidential and anonymous.

\section{Statistical analysis}

Data were analyzed by the software SPSS version 21.0 for Windowssoftware package. Descriptive statistics were used to describe the characteristics ofnurses and for comparisons between groups, chi-square, and independent-samples t-test were used. For all tests, results were considered statistically significant at $p<0.05$.

\section{Results}

The majority of the participants (82.6\%) were female, married (64\%) and had a bachelor's degree in nursing (97.7\%). The nurses were aged 23 to 47 with a mean (SD) of 30.55 (5.06) years. The mean (SD) of the nurses' work experience was $6.5(8.74)$ years in the intervention group and 7 (8.74) years in the control group. There 
were no significant differences between the two groups of nurses in terms of age, gender, marital status, academic qualifications or work experience (Table 1).

There was no significant difference between the intervention and control groups in terms of the mean score of knowledge before the intervention, but after the intervention, the mean score of knowledge increased in both groups, and the independent $\mathrm{t}$-test showed significant differences between the two groups after the intervention $(P<0.001)$. The independent $\mathrm{t}$-test showed no significant differences between the two groups in terms of the mean changes in the score of knowledge $(2.73 \pm 3.45$ in intervention group vs. $2.57 \pm 3.36$ in control group, $P=0.83$ ). In other words, teaching ethical codes using group reflection and lecture increased the nurses' ethical knowledge (Table 2).

The independent $t$-test showed no significant differences between the two groups in terms of the mean score of attitude before the intervention, but this difference was significant after the intervention $(34.7 \pm 8.44$ in intervention group vs. $29.95 \pm 9.09$ in control group, $P<$ 0.014). In the intervention group, the mean score of attitude showed a significant difference in the posttest compared to the pretest $(P=0.001)$, but no such significant difference was observed in the control group $(P=0.133$; Table 2). Nevertheless, no significant differences were observed between the two groups in terms of the mean changes in the scores of attitude before and after the intervention $(P=0.14$; Table 2$)$.

The majority of the nurses in the intervention group (84\%) believed, in the pretest stage, that observing ethical codes slowed them down, but in the posttest, only $21 \%$ of them still held this belief. In the pretest, 33 and $40 \%$ of the nurses totally agreed with the items
"Observing ethical codes increases patient satisfaction" and "Observing ethical codes leads to professional improvement", which increased to 72 and $76 \%$ in the posttest.

No significant differences were observed between the two groups before the intervention in terms of the mean score of performance, but the paired t-test showed a significant difference in the intervention group before and after the intervention $(P=0.001)$, while this difference was not significant in the control group $(P=0.077)$. The two groups were also significantly different in terms of the mean changes in their performance scores before and after intervention $(9.07 \pm 16.84$ in intervention group vs. $0.67 \pm 20.018$ in control group, $P=0.038$; Table 2). No significant relationships were observed in the present study between the changes in the scores of knowledge, attitude and performance and any of the personal demographic characteristics.

\section{Discussion}

The present findings showed that both group reflection and lecture are effective strategies for promoting nurses' knowledge of ethical codes. The results of other studies also confirm the positive effects of education through different educational strategies on nurses' knowledge of ethics. In accordance with present study the results of some other studies showed lecture have had similar cognitive learning outcomes in ethics education to some studentcentered learning strategies such as problem- based [34, 35] or team- based learning [36]. The results obtained by Farid et al. (2011) showed that teaching ethical principles by different methods can increase nurses' knowledge of ethical issues and can improve

Table 1 Demographic characteristics of subjects in the two intervention and control groups

\begin{tabular}{|c|c|c|c|c|}
\hline Characteristics & All subjects & Intervention) $n=44$ ) & Control) $n=44$ ) & $P$-value \\
\hline \multicolumn{5}{|l|}{ Age (years) } \\
\hline Mean (SD) & $30.55(5.06)$ & $30.15(4.96)$ & $30.95(5.17)$ & $0.470^{a}$ \\
\hline \multicolumn{5}{|c|}{ Years of work (years) } \\
\hline Mean (SD) & $6.75(8.74)$ & $6.5(8.74)$ & $7(8.74)$ & $0.623^{a}$ \\
\hline \multicolumn{5}{|l|}{ Sex n (\%) } \\
\hline male & $15(17.5)$ & $10(22.7)$ & $5(11.9)$ & \\
\hline female & $71(82.5)$ & $34(77.3)$ & $37(88.1)$ & $0.183^{b}$ \\
\hline \multicolumn{5}{|c|}{ n (\%) Marital status } \\
\hline single & $31(36.1)$ & $19(43.2)$ & $12(28.6)$ & \\
\hline married & $55(63.9)$ & $25(56.8)$ & $30(71.4)$ & $0.185^{b}$ \\
\hline \multicolumn{5}{|c|}{ Educational level n (\%) } \\
\hline baccalaureate & $84(6.97)$ & $43(97.7)$ & $41(97.6)$ & \\
\hline postgraduate & $2(2.4)$ & $1(2.3)$ & $1(2.4)$ & $1.000^{b}$ \\
\hline
\end{tabular}

${ }^{a}$ Chi-square test

${ }^{\mathrm{b}}$ Independent t-test 
Table 2 Comparison of the variable scores among two intervention and control groups

\begin{tabular}{|c|c|c|c|c|c|}
\hline Variables & Group & $\begin{array}{l}\text { Pretest } \\
\text { mean }\end{array}$ & $\begin{array}{l}\text { Post-test } \\
\text { mean }\end{array}$ & Mean change & $P$-value ${ }^{a}$ \\
\hline \multirow[t]{3}{*}{ Knowledge } & intervention & $10.50(2.73)$ & $13.22(3)$ & $2.73(3.45)$ & 0.001 \\
\hline & control & $10.23(2.22)$ & $12.80(3.11)$ & $2.57(3.36)$ & 0.001 \\
\hline & P-value ${ }^{b}$ & 0.628 & 0.578 & 0.83 & \\
\hline \multirow[t]{3}{*}{ Attitude } & intervention & $29.63(7.49)$ & $34.70(8.44)$ & $5.06(8.99)$ & 0.001 \\
\hline & control & $27.78(5.49)$ & $29.95(9.09)$ & 2.17 (9.15) & 0.133 \\
\hline & P-value ${ }^{b}$ & 0.197 & 0.014 & 0.14 & \\
\hline \multirow[t]{3}{*}{ Performance } & intervention & $35.79(9.49)$ & $45.46(11.39)$ & $9.07(16.84)$ & 0.001 \\
\hline & control & $35.20(7.28)$ & $38.78(11.31)$ & $0.67(20.018)$ & 0.077 \\
\hline & P-value ${ }^{b}$ & 0.747 & 0.008 & 0.038 & \\
\hline
\end{tabular}

paired t-test

Independent t- test

their ethical judgment [37]. Many studies have shown that teaching ethics has a significant positive effect on nurses' ethical decision-making [14, 38, 39]. Accordingly, Cusveller (2012) considers ethical knowledge one of the factors affecting nurses' participation in solving ethical challenges [40].

Teaching ethical codes through group reflection was also effective in improving the nurses' attitude. The mean changes in the scores of attitude before and after the intervention did not differ significantly between the two groups, which shows that teaching through lectures has also been able to improve nurses' attitude. The results of another study conducted in Iran showed that teaching ethical codes changes the attitude of nurses toward these codes and consequently strengthens their commitment to ethics in providing care [41]. The results obtained by McCrink (2011) revealed that teaching ethics to nursing students deepens their attitude toward ethical issues [42]. Nurses with a poor attitude toward ethical issues often have a poor knowledge about the subject [43]. Meanwhile, reinforcing nurses' attitude toward ethical codes is regarded as a key predicting factor in the nurses' commitment to ethical care [42]. If the aim is to change attitudes, various effective strategies should be used to pave the way for raising awareness and knowledge and consequently improving attitude, so that the best performance and conduct can be achieved [44]. The results of one study showed that different teaching methods have different effects on people's attitude, and compared to lectures and role-play, group discussion has a more significant effect [45]. The reason for the effect of lecturing on nurses' attitude in the present study may be that the nurses in this center had never been systematically exposed to the codes of nursing ethics and professional ethics, and this intervention was effectively their first exposure and thus managed to promote their knowledge and attitude in this area.

This educational course on ethical codes using group reflection improved the nurses' performance in the intervention group. The results of other studies also show the effectiveness of educational courses in improving nurses' ethical performance [46-49]. The results obtained in a study conducted by Jafarimanesh et al. showed that, although the mean score of compliance with ethical codes in nursing students who had attended ethical training courses was higher compared to the control group, the difference between them was not statistically significant [50]. The results of another study showed that, although teaching ethics to nursing students enabled them to identify ethical violations in the workplace, this training had no effect on their ethical sensitivity [48]. The disparity of findings observed may owe to the different teaching methods used.

According to some studies, teaching ethics in a group setting is more effective than the use of other methods $[26,47,49,51-53]$. In the present study, teaching by group reflection had positive effects on the knowledge, attitude and performance of nurses in relation to the codes of ethics. Group reflection is a student-centered teaching method that has been found beneficial to the development of critical thinking and the improvement of ethical decision-making skills $[26,27]$. Using these innovative methods increases participants' thinking skills and allows them to convey and reflect their experiences and have a more in-depth learning beyond the existing cultural and preferential barriers [54]. By enabling reflection on past experiences and performances, group reflection facilitates internal judgment. Furthermore, by observing other people's points of view, people can think about and reflect on problems from different angles. In one study, Callister et al. (2009) concluded that guided reflection effectively reinforces students' critical thinking and ethical reasoning [26]. The results obtained by 
Kalaitzidis et al. (2012) showed that critical thinking and problem-solving skills are strengthened in nursing students who learn ethical codes through discussions and debates about simulated scenarios and talking about other people's experiences [55]. These benefits of group reflection make it a useful and applicable teachinglearning strategy for ethical education in nursing, especially for improving nurses' ethical performance.

In the present study, the lecture method was also able to improve the learners' knowledge and attitude, but their performance remained unchanged. Since the goal of teaching is to improve awareness, change attitude and thereby behavior, active teaching methods with group participation that enable a longer-lasting learning are essential $[56,57]$. It can be concluded that teaching ethical codes by group reflection is an efficient and economical method for teaching ethics to nurses that can improve their knowledge, attitude and performance.

In the present study, no significant relationships were observed between participants' personal demographic and professional characteristics and the changes in their scores of knowledge, attitude and performance, which means that participants' characteristics did not affect the study findings. Other studies have reported different results regarding the relationship between participants' demographic variables and their ethical knowledge and attitude $[41,46,58]$.

One of the limitations of this study was that the study setting was confined to only one health center, which undermines the generalizability of the results. Future studies are therefore recommended to be conducted on larger groups of nurses from a greater diversity of health centers. Although attempts were made to select the intervention and control groups from different wards, and although the participants were asked not to exchange information with each other, such exchange may have happened in some cases, and this limitation was beyond the researcher's control.

\section{Conclusion}

The present study showed that group reflection on the ethical codes of nursing improves nurses' knowledge, attitude and performance, and this method was found to be more effective than traditional teaching methods such as lectures. This active teaching method, which can be implemented with minimal equipment, can be used to improve nurses' commitment to nursing codes of ethics. The results of this study guide nursing managers for increasing nurses' ethical performance using group reflection in continuous education courses. Nonetheless, traditional methods such as lectures can also be effective to a degree in cases where group reflection is not possible, since these methods also increase nurses' knowledge about ethical issues.

\section{Acknowledgments}

This manuscript was derived from the thesis written by Mrs. Marjan Ghanbari for Master's degree in medical-surgical Nursing. The authors would like to thank the Ghaem hospital managers and nurses who kindly took part in this investigation.

\section{Authors' contributions}

MM, MGh, and MR were responsible for the study conception and design; MGH performed the data collection; MM and MGh performed the data analysis; MM, and MGh were responsible for the drafting of the manuscript; MM, MGh, and MR made critical revisions to the paper for important intellectual content. All authors have read and approved the manuscript.

\section{Funding}

This article was extracted from a Ms. dissertation in medical-surgical nursing, which was financially supported by the Research Vice-chancellor of Shiraz University of Medical Sciences (grant No. 11293). The funder had no role in the design of the study, nor in the collection, analysis, and interpretation of the data and in writing the manuscript.

Availability of data and materials

Data available by contacting the corresponding author.

\section{Declarations}

Ethics approval and consent to participate

This study was approved by the research ethics committee of Shiraz University of Medical Sciences (No: IR.SUMS.REC.1395.55). It was also registered in the Iranian Registry of Clinical Trials (No:

IRCT2016070317546N6). After receiving explanations about the study, all participants signed a written consent form. They were assured that rejecting participation in the study would have no effect on their professional status and their data would be keptconfidential and anonymous.

\section{Consent for publication}

Not Applicable.

\section{Competing interests}

The authors declare there are no competing interests.

\section{Author details}

'Department of Nursing, School of Nursing and Midwifery, Shiraz University of Medical Sciences, Shiraz, Iran. ${ }^{2}$ School of Nursing and Midwifery, Shiraz University of Medical Sciences, Shiraz, Iran. ${ }^{3}$ Community Based Psychiatric Care Research Center, Department of Nursing, School of Nursing and Midwifery, Shiraz University of Medical Sciences, Zand St., Namazee Sq, Shiraz 7193613119, Iran.

Received: 29 September 2020 Accepted: 22 October 2021

Published online: 06 November 2021

\section{References}

1. Zahedi F, Sanjari M, Aala M, Peymani M, Aramesh K, Parsapour A, et al. The Code of Ethics for Nurses. Iran J Public Health. 2013;42(Supple. 1):1-8.

2. Nursing Ethics codes in Islamic Republic of Iran. Iranian Nursing Organization. Available in http://ino.ir/tabid/40/ctl/Article View/mid/384/ articled/1074/language/fa_IR. [ in persian ] 2010.

3. Zirak M, Moghaddsiyan S, Abdollahzadeh F, Rahmani A. Moral Development of Nursing Students of Tabriz University of Medical Sciences. Iran J Med Ethics History Med. 2011;4(7):10-9 [in Farsi, English abstract].

4. Mohajjel-Aghdam A, Hassankhani H, Zamanzadeh V, Khameneh S, Moghaddam S. Knowledge and performance about nursing ethic codes from Nurses' and Patients' perspective in Tabriz teaching hospitals, Iran. J Caring Sci. 2013;2(3):219-27. https://doi.org/10.5681/jcs.2013.027.

5. Mohajjel Aghdam A, Hassankhani H, Zamanzadeh H, Khameneh S, Moghaddam S. Knowledge and Practice of Nursing Code of Ethics for Nurses to Hospitals in Tabriz, Iran. J Med History. 2012;5(17):113-40 [in persian].

6. Momennasab M, Rahmanian Kooshkaky A, Torabi Zadeh K. Comparison of Commitment to Nursing Practice Ethical Code from the Viewpoint of 
Patient, Nurses and Nursing Managers in General Wards of Educational Hospitals, Shiraz. Nursing Ethics. 2015: [in persian].

7. Bijani M, Ghodsbin F, Javanmardi Fard S, Shirazi F, Sharif F, Tehranineshat B. An evaluation of adherence to ethical codes among nurses and nursing students. J Med Ethics History Med. 2017;10(6):2-8.

8. Barroso C, Abureu W. Developing ethical thinking in clinical setting: a Cace study. Nurs Ethics. 2015;17(2):661-7.

9. Keçeci A, Bulduk S, Oruc D, Celik S. Academic dishonesty among nursing students: a descriptive study. Nurs Ethics. 2011;18(5):725-33. https://doi. org/10.1177/0969733011408042.

10. Abedi G, Shojaee J, Moosazadeh M, Rostami F, Nadi A, Abedini E, et al. Awareness and Observance of Patient Rights from the Perspective of Iranian Patients: A Systematic Review and Meta-Analysis. Iran J Med Sci. 2017;42(3): 227-34

11. Sadeghi R, Ashktorab T. Ethical Problems of Observed by Nursing Students: a Qualitative Research. J Med Ethics History Med. 2011;5(12):44-66 [in persian].

12. Klimova BF, Semradova I. Innovation in tertiary education and professional codes of ethics. Procedia Soc Behav Sci. 2013;83(11):161-4. https://doi.org/1 0.1016/j.sbspro.2013.06.031.

13. Jafari $\mathrm{H}$, Khatony $\mathrm{A}$, Abdi A, Jafari F. Nursing and midwifery students attitudes towards principles of medical ethics in Kermanshah. Iran BMC Medical Ethics. 2019;20(26):1-6. https://doi.org/10.1186/s12910-019-0364-z.

14. Poorbandbeni ME, Sadeghi R, Salsali M, Borhani F. Factors Influencing Nurses' Active Participation in Solving Ethical Problems Encountered in Clinical Practice. J Faculty Nurs Midwife Uremieh. 2013;11(4):42-54 [in persian].

15. Zirak M, Moghadasian S, Abdollahzadeh F, Rahmani A. The Study of Level of Ethical Development in Nurses Working in Training-Treatment Hospitals Affiliated in Tabriz University of Medical Sciences, Tabriz, Iran. Iran J Med Ethics History Med. 2012;6(3):9-17 [in Farsi, English abstract].

16. Jahanpour F, Paimard A, Pouladi S, Azodi F, Shayan P, Azodi P, et al. Comparing the durability of professional ethics' learning in two methods of group discussion and multimedia software. Res J Med Sci. 2016;10(3):120-3.

17. Abbaszadeh A, Torabi M, Borhani F, Shamsaie F. The place of ethics education in nursing in Iran. Akhlagh-e Zisti (ie, Bioethics Journal). 2016; 5(17):117-46 [in Persian].

18. Afshar L, Joolaee $S$, Vaskouei $K$, Bagheri A. Nursing ethics priorities from nurses' aspects: a national study. Med Ethics History Med. 2013;6(3):54-63 [in Persian].

19. Moattari M, Abedi H. Nursing Students Experiences in Reflective Thinking: a Qualitative Study. Iran J Med Educ. 2008;8(1):101-12 [in persian].

20. Abedini Z, Jafarbeglu E, Raeesi M, Dadkhah TT. The effect of reflection in nursing education : nursing students. Iran J Nurs. 2011;71(24):74-82 [in persian].

21. Fowler J. Experiential learning and its Faciliation. Nurs Educ Today. 2010; 28(4):427-60. https://doi.org/10.1016/j.nedt.2007.07.007.

22. Chong M. Is reflective practice a useful task for students nurses? Asian Nurs Res. 2009;3(3):20-120. https://doi.org/10.1016/S1976-131 7(09)60022-0

23. Carthy $\mathrm{M}$, Jane $\mathrm{Cl}$, Touhy D. Lecturers Expriences of facilitating guided group reflection with pre-registration BSC nursing students. Nurs Ethics. 2013;33(12):36-40.

24. Grant A, McKimm J, Murphy F. Developing reflective practice: a guide for medical students, doctors and teachers Chichester: ohn Wiley \& Sons, Itd: 2017.

25. Ghasemi AM. The effect of group reflection on thinking styles and critical thinking skills in nursing of Alzahra heart center shiraz [thesis for MS of nursing [in persian]]. Shiraz: Shiraz University of Medical Science; 2012

26. Callister LC, Luthy KE, Thompson P, Memmott RJ. Ethical Reasoning in Baccalaureate Nursing Students. Nurs Ethics. 2009;16(4):501-7. https://doi. org/10.1177/0969733009104612.

27. Dinc L, Gorgula RS. Teaching Ethics in Nursing. Nurs Ethics. 2002;9(3):261-9. https://doi.org/10.1177/096973300200900305.

28. Laranjeira C. A ethical reflection about nursing Care in Terminal Diseases: a Portuguese report. Eur Psychiatry. 2015;30(4):330-416. https://doi.org/10.101 6/S0924-9338(15)31871-X.

29. Bulman C, Lathlean J, Gobbi M. The concept of reflection in nursing: qualitative findings on student and teacher perspectives. Nurs Educ Today. 2012;32(5):8-13. https://doi.org/10.1016/j.nedt.2011.10.007.
30. Potter C. Leadership development: an applied comparison of Gibbs reflective cycle and Scharmer's theory U. Potter. 2015;47(6):336-42. https:// doi.org/10.1108/ICT-03-2015-0024.

31. O'Connor A. The use of reflective practice on critical incidents, in a neonatal setting, to enhance nursing practice. J Neonatal Nursing. 2008;14(3):87-93. https://doi.org/10.1016/j.jnn.2007.12.014.

32. Shad FZ. The effect of group reflection toward spiritual care on nursing Students' spiritual well-being and their Prespective in Shiraz University of medical science thesis for MS of nursing [in persian]: Shiraz University of medical science; 2014

33. Polit DF, Beck CT. The content validity index: are you sure know What's being Repored? Critique and recommendations. Res Nurs Health. 2006;29(5): 489-586. https://doi.org/10.1002/nur.20147.

34. Khoshnevisasl P, Sadeghzadeh M, Mazloomzadeh S, Hashemi Feshareki R, Ahmadiafshar A. Comparison of problem-based learning with lecture-based learning. Iran Red Crescent Med J. 2014;16(5):e5186. https://doi.org/10.5812/ ircmj.5186.

35. Khatiban M, Falahan S, Amini R, Farahanchi A, Soltanian A. Lecture-based versus problem-based learning in ethics education among nursing students. Nurs Ethics. 2019;26(6):1753-64. https://doi.org/10.1177/0969733018767246.

36. Ozgonul L. Alimoglu M. Comparison of lecture and team-based learning in medical ethics education. Nurs Ethics. 2019;26(3):903-13. https://doi.org/1 $0.1177 / 0969733017731916$

37. Farid A, Saadi Poor A, Karimi Y. Effectivness of direct training, cognitive training, ethics, values clarification and complications on moral judgments of students. J Psycol. 2011;19(5):96-116 [in persian].

38. Marshal B, Papps E, Sinelair J. Nursing students experiences of ethical issues in clinical practice : a New Zealand study. Nurs Ethics. 2016;17(3):1-7.

39. Y-s K, S-w K, J-a A. Moral sensitivity relation to the application of the code of ethics. Nurs Ethics. 2014;20(4):470-8.

40. Cusveller B. Nurses serving on clinical ethics committees: a qualitative exploration of a competency profile. Nurs Ethics. 2012;19(3):431-40. https:// doi.org/10.1177/0969733011426817.

41. Mokhtari Lakeh N, Nafar M, Ghanbari Khanghah A, Kazemnezhad Leili E. Nursing Students' Views on Code of Ethics, Commitment to The Ethic of Academic Dishonesty and Neutralization Behaviors. Holistory Nurs Midwife. 2014;24(1):64-9 [in persian].

42. McCrinck A. Nursing student attitude towards academic misconduct, the code of ethics for nurses and their commitment to the ethic of caring [Tesis for PHD of nursing]. New York: Dowling College; 2009.

43. Mukul M, Anu B, Prassana M, Abhishek S, Adiba S, Rajesh DR. Current status of knowledge, attitudes and practices towards healthcare ethics among doctors and nurses from northern India- a multiple study. Nurs Ethics. 2013; 28(2):102-7.

44. Hildingsson I, Thomas J. Woman's Prespectives on maternity Services in Sweden: problems and solutions. J Midwife Woman's Health. 2008;12(25): 126-35.

45. Saeedy RM, Kazemi Y. Comparison of Teaching Methods Lecture, Group Discussion and Role-play on a Change of Attitude Targets. J Teach Learn Psychol. 2009;11(1):29-42 [in persian].

46. Numminen $\mathrm{O}$, Leino-Kilip H, Katajisto J. Nurse educators teaching of codes of ethics. Nurs Prof J. 2010;30(16):124-31. https://doi.org/10.1016/..nedt.2009. 06.011 .

47. Alizadeh T, Amiri S, Taher Neshst H, Talebi H. Comparing the effectiveness of training Kohlberg's hypothetical dilemmas, training the real life Dilemmas' and training positive emotion induction on moral decision making. J Knowledge Res Appl Psychol. 2014;16(3):13-24 [in persian].

48. Baykara ZG, Demir SG, Yaman S. The Effects of Ethics Training on Students Recognizing Ethical Violation and Developing Moral Sensivity. Nurs Ethics. 2014:11(7):1-15.

49. Vahedian Azimi A, Alhani F. The Challenges of Education in Ethical Decisions. J Med Ethics History Med. 2009;9(3):2-8 [in persian].

50. Jafari Manesh H, Ranjbaran M, Vakilian K, Tajik R, Almasi-Hashiani A. Nursing's code of ethics: a survey of respecting the code among nursing students. Iran J Med Ethics History. 2013;6(6):46-54 [in persian].

51. Numminen O, Leino-Kilip H. Nursing Studentts ethical decision- making: a review of the literature. Nurse Educ Today. 2009;10(9):380-94.

52. Cummings R, Maddux M. D., Cladianos a, Richmond a. moral reasoning of education students: the effect of direct instruction in moral development theory and participation in moral dilemma Discution. J Account Educ. 2010; 12(20):621-44. 
53. Park M, Kjervik D, Crandell J, Oermann MH. The relationship of ethics education to moral sensitivity and moral reasoning skills of nursing students. Nurs Ethics. 2012;19(4):568-80. https://doi.org/10.1177/0969733 011433922.

54. Sandard J. The use of reflection in medical education. Med Teach. 2009; 31(8):95-104.

55. Kalaitzidis E, Schmitz K. A study of an ethics education topic for Undercraduate nursing students. Nurs Educ Today. 2012;32(69):111-5. https://doi.org/10.1016/j.nedt.2011.02.006.

56. Razavi S, Mardani M, Avizhgan M. Increase The Continuity of Learning the Lesson of Histology With Discution. Iran J Med Educ. 2012;11(9):1162-70 [in persian].

57. Lakdashti A, Yousefi R, Khatiri K. The effect of educational simulator Software's on learning and remembering in university students and comparing it with traditional methods. Inform Commun Technol Educ Sci J. 2011;13(5):6-22 [in persian].

58. Ghalgeh M, Zakeri Z, Rezaee N, Abedzadeh R. Physicians and nurses awareness and function about Patients' right character in Zahedan. Nurs Ethics. 2010;69(3):57-63 [in persian]

\section{Publisher's Note}

Springer Nature remains neutral with regard to jurisdictional claims in published maps and institutional affiliations.

Ready to submit your research? Choose BMC and benefit from:

- fast, convenient online submission

- thorough peer review by experienced researchers in your field

- rapid publication on acceptance

- support for research data, including large and complex data types

- gold Open Access which fosters wider collaboration and increased citations

- maximum visibility for your research: over $100 \mathrm{M}$ website views per year

At BMC, research is always in progress.

Learn more biomedcentral.com/submissions 